Article

\title{
Forward Current Transport Properties of AlGaN/GaN Schottky Diodes Prepared by Atomic Layer Deposition
}

\author{
Hogyoung Kim ${ }^{1, * \mathbb{C}}$, Seok Choi $^{2}$ and Byung Joon Choi ${ }^{2, *}$ \\ 1 Department of Visual Optics, Seoul National University of Science and Technology (Seoultech), \\ Seoul 01811, Korea \\ 2 Department of Materials Science and Engineering, Seoul National University of Science and \\ Technology (Seoultech), Seoul 01811, Korea; yeshuaarmy@naver.com \\ * Correspondence: hogyoungkim@seoultech.ac.kr (H.K.); bjchoi@seoultech.ac.kr (B.J.C.); \\ Tel.: +82-2-970-6233 (H.K.)
}

Received: 14 January 2020; Accepted: 21 February 2020; Published: 24 February 2020

check for updates

\begin{abstract}
Atomic layer deposited $\mathrm{AlGaN}$ on $\mathrm{GaN}$ substrate with different thicknesses was prepared and the electron transport mechanism of AlGaN/GaN Schottky diodes was investigated. Above $348 \mathrm{~K}$, both 5 and $10 \mathrm{~nm}$ thick AlGaN showed that the thermionic emission model with inhomogeneous Schottky barrier could explain the forward current transport. Analysis using a dislocation-related tunneling model showed that the current values for $10 \mathrm{~nm}$ thick AlGaN was matched well to the experimental data while those were not matched for $5 \mathrm{~nm}$ thick AlGaN. The higher density of surface (and interface) states was found for $5 \mathrm{~nm}$ thick AlGaN. In other words, a higher density of surface donors, as well as a thinner AlGaN layer for $5 \mathrm{~nm}$ thick AlGaN, enhanced the tunneling current.
\end{abstract}

Keywords: AlGaN/GaN; dislocation-related tunneling; surface donors

\section{Introduction}

Among III-nitride materials, $\mathrm{AlGaN} / \mathrm{GaN}$ heterostructures have gained much interest due to the applications in high-temperature, high-voltage, and high-frequency electronic devices [1-3]. In particular, AlGaN/GaN-based high electron mobility transistors (HEMTs) are commonly used because two-dimensional electron gas (2DEG) located just below the AlGaN/GaN interface can be easily obtained with high conductivity. The electron sheet densities of $10^{13} \mathrm{~cm}^{-2}$ were found to be obtained by using $\mathrm{AlGaN}$ barriers when the $\mathrm{Al}$ content is typically 20-25\% [3]. However, the large reverse leakage current occurring in AlGaN/GaN HEMTs increase the noise at low-frequency and leads to current collapse, limiting the applicability of such devices [4]. Most of all, the leakage current flowing through the extended defects such as threading dislocations (TDs) are inevitably generated because of the large lattice mismatch and the different thermal expansion coefficients between (In,Al)GaN film and sapphire (or $\mathrm{Si}$ ) substrate [5-7].

Several works have been performed to investigate the current transport mechanisms in AlGaN-based devices. The barrier thinning which was caused by unintentional surface-defect donors was found to enhance the tunneling current, causing large leakage currents through (Al)GaN Schottky interfaces [8]. The reverse leakage current in AlGaN/GaN was successfully analyzed in terms of a trap-assisted Poole-Frenkel (PF) emission [9]. Ha et al. suggested that the dominant current transport mechanism in $\mathrm{AlGaN} / \mathrm{GaN}$ Schottky diodes with $\mathrm{CF}_{4}$ plasma treatment is the $\mathrm{PF}$ emission arising from fluorine-related deep traps into the continuum states related to dislocations [10]. It was found that the AlInN/GaN Schottky diode has a higher Schottky barrier but a larger reverse leakage current than an $\mathrm{AlGaN} / \mathrm{GaN}$ Schottky diode, which was attributed to higher defect density and higher tunneling current [11]. In atomic layer deposition (ALD), $\mathrm{Al}_{2} \mathrm{O}_{3}, \mathrm{Al}-\mathrm{Al}$ and $\mathrm{Al}-\mathrm{O}-\mathrm{H}$ bonds have been 
suppressed significantly by replacing the conventional $\mathrm{H}_{2} \mathrm{O}$ source with $\mathrm{O}_{3}$ and the density of positive bulk/interface charges was reduced to as low as $9 \times 10^{11} \mathrm{~cm}^{-2}$ [12].

The ALD growth having a low-temperature and self-limiting growth mechanism can offer many advantages such as high uniformity, high conformality, and accurate thickness control [13], which can be applied to temperature-sensitive devices and flexible substrates like polymers. The $\mathrm{Al}_{x} \mathrm{Ga}_{1-x} \mathrm{~N}$ growth by ALD is utilized to modulate the bandgap from $6.2 \mathrm{eV}$ (AlN) to $3.4 \mathrm{eV} \mathrm{GaN}$, which is beneficial to design AlGaN-based devices. However, there is limited investigation into ALD-AlGaN and GaN [14,15], as compared to the intensive investigation of ALD-AlN. In this work, we grew AlGaN on GaN substrate by ALD and characterized the forward current transport properties in AlGaN/GaN Schottky contacts.

\section{Materials and Methods}

The ALD growth of AlGaN on c-plane (0001) GaN substrate was carried out using a thermal ALD system after native oxide removal process in an $\mathrm{HCl}: \mathrm{H}_{2} \mathrm{O}(1: 1)$ solution. Both 5 and $10 \mathrm{~nm}$ thick AlGaN layers were grown at $335^{\circ} \mathrm{C}$ using trimethylaluminum (TMA), triethylgallium (TEG), and $\mathrm{NH}_{3}$ as $\mathrm{Al}, \mathrm{Ga}$, and $\mathrm{N}$ precursors, respectively. The ALD reaction was composed of TMA (TEG) feeding, $\mathrm{N}_{2}$ purge, $\mathrm{NH}_{3}$ feeding, and $\mathrm{N}_{2}$ purge. AlGaN growth was done by the combination of $\mathrm{GaN}$ and AlN reactions with a pulse ratio of $1: 1$, corresponding to $\mathrm{Al}_{0.85} \mathrm{Ga}_{0.15} \mathrm{~N}$. According to the $\mathrm{X}$-ray photoelectron spectroscopy (XPS) analysis, we found that the dominant peak in the $\mathrm{Al} 2 p$ core-level spectra shifted to lower binding energy with the increase of AlN thickness due to a strong Al-Al peak, which was associated with the strain relaxation generated from the lattice mismatch between AlN and GaN [16]. In other words, when the thickness of AlN exceeded $\sim 10 \mathrm{~nm}$, the strain relaxation affected the overgrown AlN film quality. Figure 1a shows the XPS core-level spectrum obtained from $10 \mathrm{~nm}$ thick $\mathrm{AlGaN}$ surface, revealing no clear evidence of the $\mathrm{Al}-\mathrm{Al}$ peak. This indicates that the effect of strain relaxation is insignificant. In order to minimize the effect of strain relaxation, we prepared relatively thin $\mathrm{AlGaN}$ layers such as 5 and $10 \mathrm{~nm}$ in this work. In order to characterize the electrical properties, AlGaN/GaN Schottky diodes were fabricated with a $50 \mathrm{~nm}$ thick Pt front contact (diameter: $500 \mu \mathrm{m}$ ) and a $100 \mathrm{~nm}$ thick $\mathrm{Al}$ contact was deposited over the entire back surface. Figure $1 \mathrm{~b}$ shows the schematic layer structures of the devices. Current-voltage $(I-V)$ and capacitance-voltage $(C-V)$ measurements were carried out with a Keithley 238 current source and an HP 4284A LCR meter, respectively.
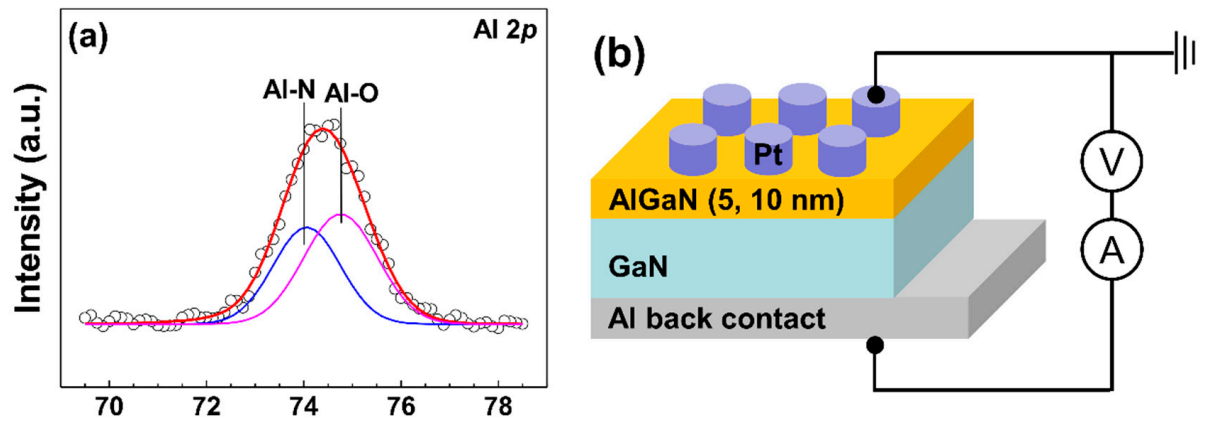

Figure 1. (a) X-ray photoelectron spectroscopy (XPS) Al $2 p$ core-level spectrum obtained from $10 \mathrm{~nm}$ thick AlGaN surface and (b) schematic layer structures of the devices.

\section{Results}

Figure 2 shows the forward $I-V$ data obtained at various temperatures. Using the thermionic emission (TE) model [17], the barrier heights were calculated. Here, we calculated the theoretical effective Richardson constant using the equation, $A^{*}=2 \pi q m^{*} k^{2} / \mathrm{h}^{3}$, where $h$ is Plank's constant and $m^{*}$ is the effective electron mass in $\mathrm{AlGaN}$ [18] and obtained the Richardson constant of $\mathrm{Al}_{0.85} \mathrm{Ga}_{0.15} \mathrm{~N}$ as $40.0 \mathrm{Acm}^{-2} \mathrm{~K}^{-2}$. The barrier height vs. temperature is described as $\Phi_{B}=\bar{\Phi}_{B}-q \sigma_{0}^{2} / 2 k T$, where 
$\bar{\Phi}_{B}$ is the zero-bias mean barrier height and $\sigma_{0}$ is the standard deviation. The plots of $\Phi_{B}$ vs. $1 / 2 k T$ are shown in Figure 3a. The barrier heights for $10 \mathrm{~nm}$ thick AlGaN are higher than those for $5 \mathrm{~nm}$ thick AlGaN. The linear fits to plots of $\Phi_{B}$ vs. 1/2kT were applied to the temperature ranges of $325-425 \mathrm{~K}$ and 348-435 K, respectively, for 5 and $10 \mathrm{~nm}$ thick AlGaN. The linear fits yielded the values of $\bar{\Phi}_{B}=1.55 \mathrm{eV}$ and $\sigma_{0}=0.19 \mathrm{~V}$ for $5 \mathrm{~nm}$ thick AlGaN and the values of $\bar{\Phi}_{B}=1.98 \mathrm{eV}$ and $\sigma_{0}=0.22 \mathrm{~V}$ for $10 \mathrm{~nm}$ thick AlGaN. The modified Richardson plot with the lateral barrier inhomogeneity considered is described as follows:

$$
\ln \left(I_{0} / T^{2}\right)-q^{2} \sigma_{0}^{2} / 2 k^{2} T^{2}=\ln \left(A A^{*}\right)-\bar{\Phi}_{B} / k T
$$

where $I_{0}$ is the reverse bias saturation current and $A$ is the Schottky contact area. Figure $3 b$ shows plots of $\ln \left(I_{0} / T^{2}\right)-q^{2} \sigma_{0}^{2} / 2 k^{2} T^{2}$ vs. $1 / k T$. The intercepts at the ordinate produced modified Richardson constants of 44.8 and $44.4 \mathrm{Acm}^{-2} \mathrm{~K}^{-2}$, respectively, for 5 and $10 \mathrm{~nm}$ thick AlGaN. These values are similar to the theoretical value of $40.0 \mathrm{Acm}^{-2} \mathrm{~K}^{-2}$ for $\mathrm{Al}_{0.85} \mathrm{Ga}_{0.15} \mathrm{~N}$. Therefore, the forward current flows for AlGaN/GaN Schottky contacts can be explained by the TE model with Schottky barrier inhomogeneity.

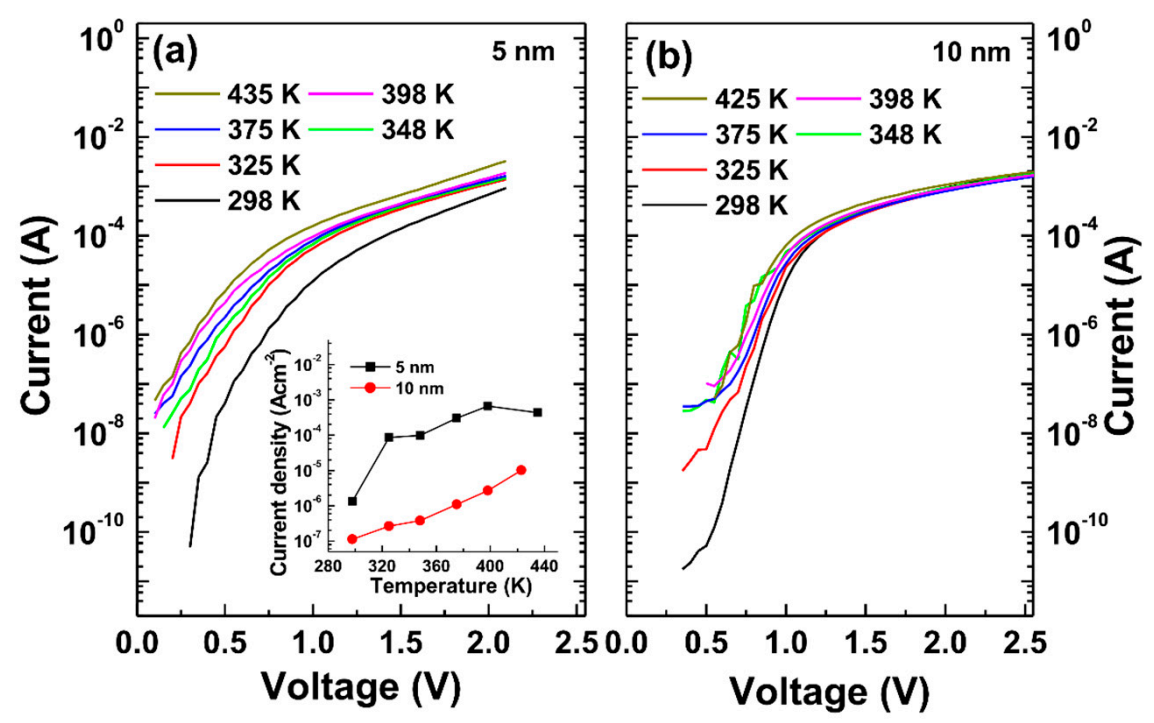

Figure 2. Current-voltage ( $I-V)$ data obtained at various temperatures: (a) $5 \mathrm{~nm}$ and (b) $10 \mathrm{~nm}$ thick AlGaN samples. The inset in (a) shows the reverse leakage current densities at $-10 \mathrm{~V}$.
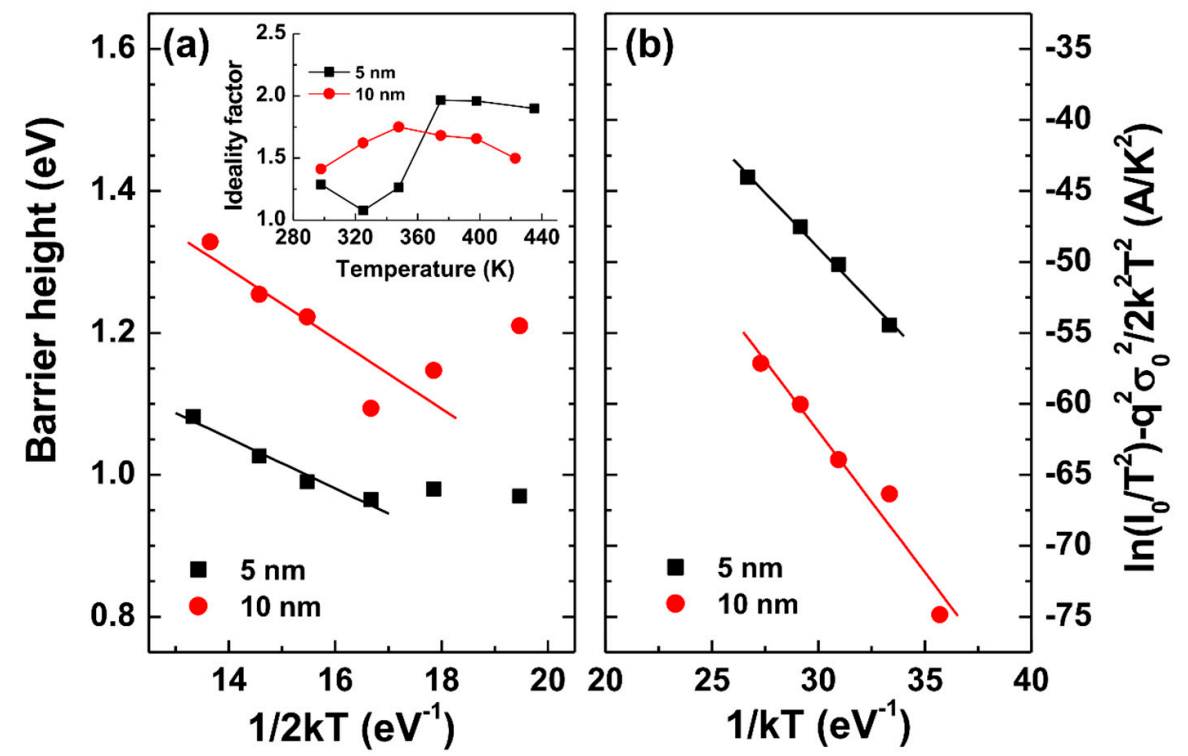

Figure 3. (a) Barrier height vs. $1 / 2 k T$ plots and (b) modified Richardson plots. The inset in (a) shows the ideality factors. 
To clarify the current transport mechanism more thoroughly, other transport components were considered comprehensively. The total current $I_{T O T}$, was assumed to be the combination of different transport mechanisms, given by [19]:

$$
\begin{gathered}
I_{T O T}=I_{T E}+I_{G R}+I_{T U}+I_{L E} \\
I_{T E}=I_{T E}^{0}\left[\exp \left\{q\left(V-I R_{S}\right) / k T\right\}-1\right] \\
I_{G R}=I_{G R}^{0}\left[\exp \left\{q\left(V-I R_{S}\right) / 2 k T\right\}-1\right] \\
I_{T U}=I_{T U}^{0}\left[\exp \left\{q\left(V-I R_{S}\right) / E_{0}\right\}-1\right] \\
I_{L E}=\left(V-I R_{S}\right) / R_{S h}
\end{gathered}
$$

where $I_{T E}$ is the TE current, $I_{G R}$ is the generation-recombination (GR) current, $I_{T U}$ is the tunneling current (TU), and $I_{L E}$ is the leakage current. $I_{T E}^{0}=A A^{*} T^{2} \exp \left(-\Phi_{B} / k T\right)\left(\Phi_{B}\right.$ : barrier height), $I_{G R^{\prime}}^{0}$ and $I_{T U}^{0}$ are the saturation currents of TE, GR, and TU components, respectively. $E_{0}=E_{00} \operatorname{coth}\left(E_{00} / k T\right)$ is a parameter, where $E_{00}=q \hbar / 2\left(N_{d} / m_{e} \varepsilon_{S}\right)^{1 / 2}$ is the tunneling characteristic energy. $R_{S}$ is the series resistance, which can be extracted from the curves where the $I-V$ data begin to saturate and $R_{S h}$ is the shunt resistance. We fitted the experimental forward $I-V$ curves to theoretical $I-V$ data by taking $I_{G R}^{0}, I_{G R}^{0}, I_{T U^{\prime}}^{0}$ and $E_{0}$ as fitting parameters. The experimental and fitted data at $298 \mathrm{~K}$ for $10 \mathrm{~nm}$ thick AlGaN are shown in Figure 4 as an example.

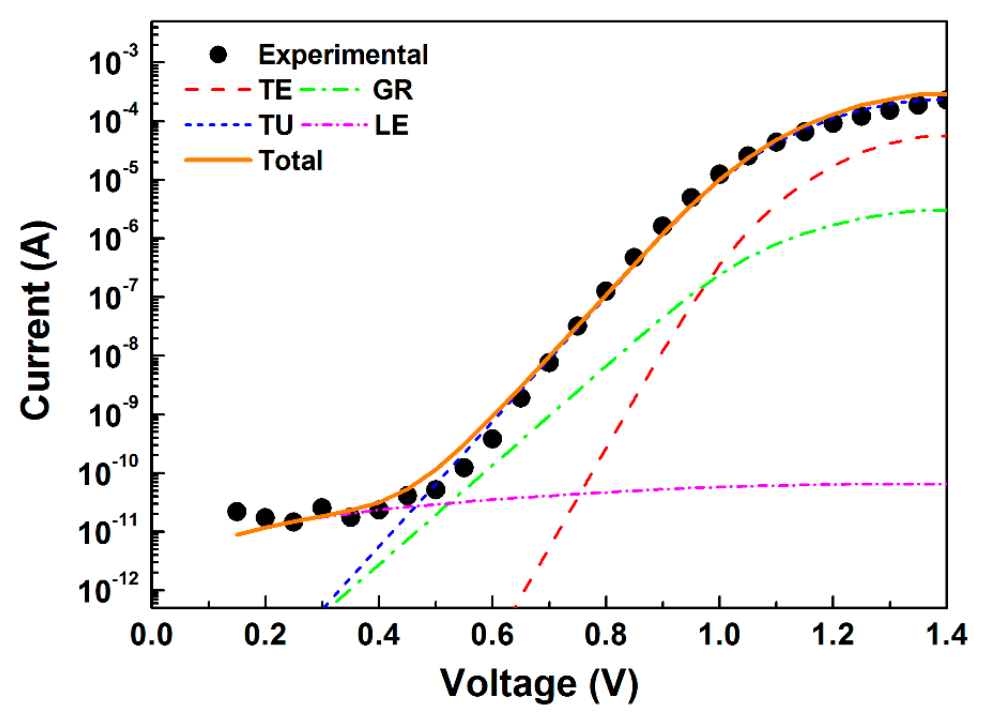

Figure 4. The fitting results of the forward $I-V$ data at $298 \mathrm{~K}$ for a $10 \mathrm{~nm}$ thick AlGaN sample are shown.

The barrier heights were calculated from $I_{T E}^{0}$ values of the TE component at different temperatures, which are shown in Figure 5a. The barrier heights showed very little temperature dependence for $5 \mathrm{~nm}$ thick AlGaN, but these increased slightly with temperature for $10 \mathrm{~nm}$ thick AlGaN. The relation between barrier height and bandgap energy $\left(E_{g}\right)$ is roughly approximated as $\Phi_{B} \cong E_{g} / 3$ [20]. The bandgap of $\mathrm{Al}_{0.85} \mathrm{Ga}_{0.15} \mathrm{~N}$ was found to be about $5.65 \mathrm{eV}$ based on the argument by Pelá et al. [21]. Then, the barrier height can be obtained as $1.88 \mathrm{eV}$. This value is higher than the values in Figure 5a but is closer to the zero-bias mean barrier height of $1.98 \mathrm{eV}$ for $10 \mathrm{~nm}$ thick AlGaN. The flat-band barrier height was also determined using the barrier height and the ideality factor $(n)$, which is given by [22]:

$$
\Phi_{B f}=n \Phi_{B}-(n-1) k T / q \ln \left(N_{C} / N_{D}\right)
$$

where $N_{C}$ is the density of states at the conduction band and $N_{D}$ is the carrier concentration. Under the flat-band condition, the electric field in the semiconductor is zero and the effects of image force 
lowering and tunneling on the $I-V$ properties are negligible. Figure $5 \mathrm{~b}$ shows the obtained flat-band barrier heights. At higher temperatures (above $348 \mathrm{~K}$ ), the values for both samples are closer to the value of $1.88 \mathrm{eV}$.
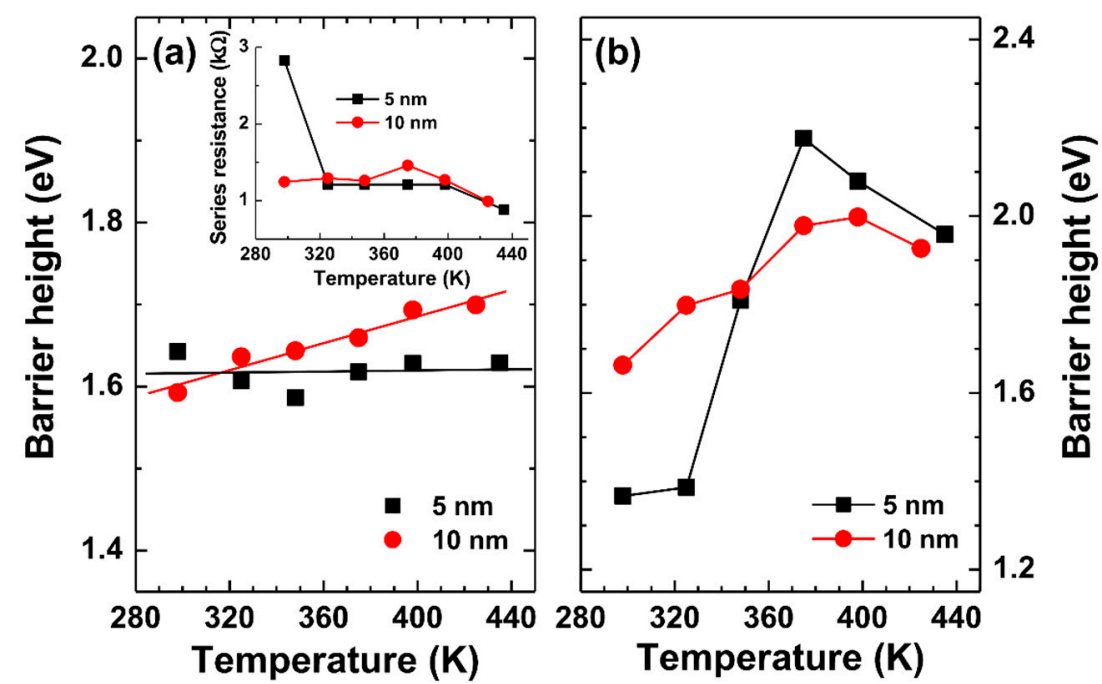

Figure 5. (a) Barrier heights obtained from thermionic emission (TE) component and (b) flat-band barrier heights. The inset in (a) shows the series resistances obtained from the fitting.

According to the dislocation-governed tunneling current model, the tunneling saturation current at $0 \mathrm{~K}$ can be described as [20]:

$$
I_{T U}^{0}(0)=q A v_{D} N_{d i s} \exp \left(-\Phi_{B} / E_{t}(0)\right)
$$

where $v_{D}\left(\sim 1.5 \times 10^{13} \mathrm{~s}^{-1}\right.$ [23] $)$ is the Debye frequency and $N_{d i s}$ is the dislocation density. Figure 6 shows the tunneling saturation current $\left(I_{T U}^{0}\right)$ and the barrier energy $\left(E_{t}\right)$. We extrapolated the linear fitting to the data in Figure 6 to attain $I_{T U}^{0}$ and $E_{t}$ at $0 \mathrm{~K}$. The barrier energy revealed a weak temperature dependence, indicating that the tunneling current is dominant. The tunneling saturation currents deviated from linearity at low temperatures and thus, some data were not included in the fitting. Finally, the dislocation densities were calculated to be $6.16 \times 10^{5}$ and $1.38 \times 10^{10} \mathrm{~cm}^{-2}$, respectively, for 5 and $10 \mathrm{~nm}$ thick AlGaN. Figure 7a shows the atomic force microscopy (AFM) surface image of $5 \mathrm{~nm}$ thick AlGaN measured over $1 \mu \mathrm{m} \times 1 \mu \mathrm{m}$ scan area. The randomly distributed dark pits are observed over all the scan area. The small pits for GaN surface are known to represent the threading dislocations (TDs) with mixed and screw components where step edges meet, and pure edges meet when the components are on a terrace [24]. The values of $\mathrm{TDs}$ for $\mathrm{Al}_{0.7} \mathrm{Ga}_{0.3} \mathrm{~N}$ grown by metalorganic chemical vapor deposition (MOCVD) were also obtained from AFM images, which were found to be $2.5 \times 10^{9} \mathrm{~cm}^{-2}$. [25]. In this regard, we assumed that the density of pits are comparable to the density of TDs. The densities of these pits were measured to be $5.8 \times 10^{10} \mathrm{~cm}^{-2}$ for $5 \mathrm{~nm}$ thick AlGaN. As shown in Figure $7 \mathrm{~b}$ the AFM image of $10 \mathrm{~nm}$ thick AlGaN does not reveal clearly distributed dark pits (though dark regions are observed). Even though we tried to obtain AFM images from different regions, we could not get an image similar to that of the $5 \mathrm{~nm}$ thick AlGaN. Nevertheless, it is possible to assume that the density of TDs would not decrease (or increase) significantly after increasing the AlGaN thickness from 5 to $10 \mathrm{~nm}$. Both 5 and $10 \mathrm{~nm}$ thick AlGaN might have similar densities of TDs. Consequently, the density of TDs from AFM is similar to the value of $1.38 \times 10^{10} \mathrm{~cm}^{-2}$ from $10 \mathrm{~nm}$ thick $\mathrm{AlGaN}$ but is much higher than that from $5 \mathrm{~nm}$ thick AlGaN. This implies that the dislocation-related tunneling current transport is the dominant mechanism in $10 \mathrm{~nm}$ thick AlGaN. However, such a mechanism cannot be applied to $5 \mathrm{~nm}$ thick AlGaN. 


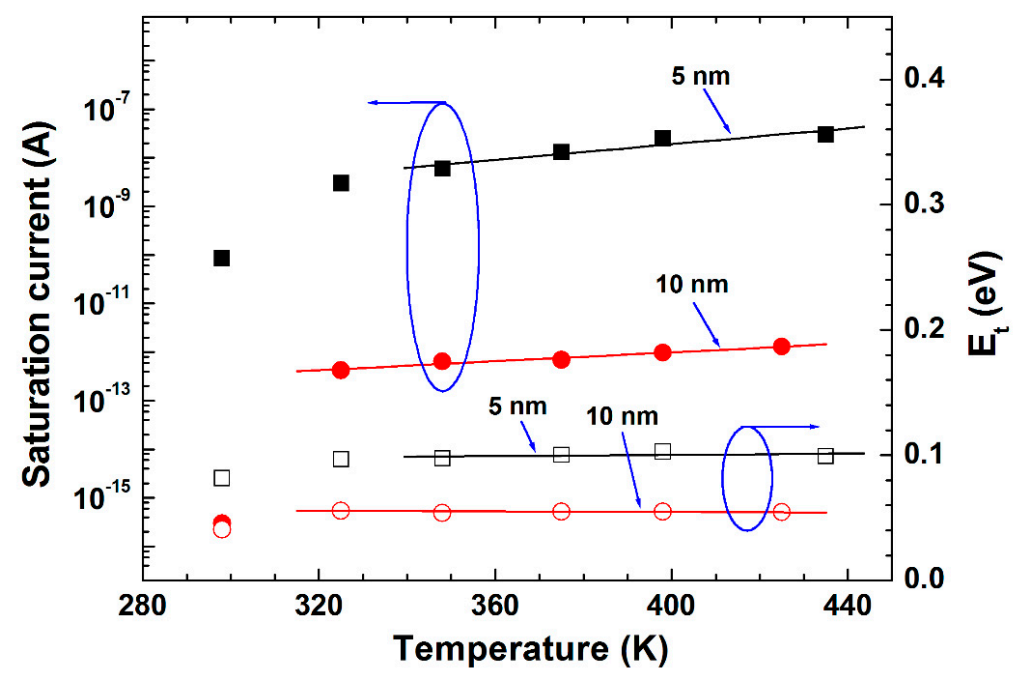

Figure 6. Tunneling saturation current and barrier energy vs. temperature.
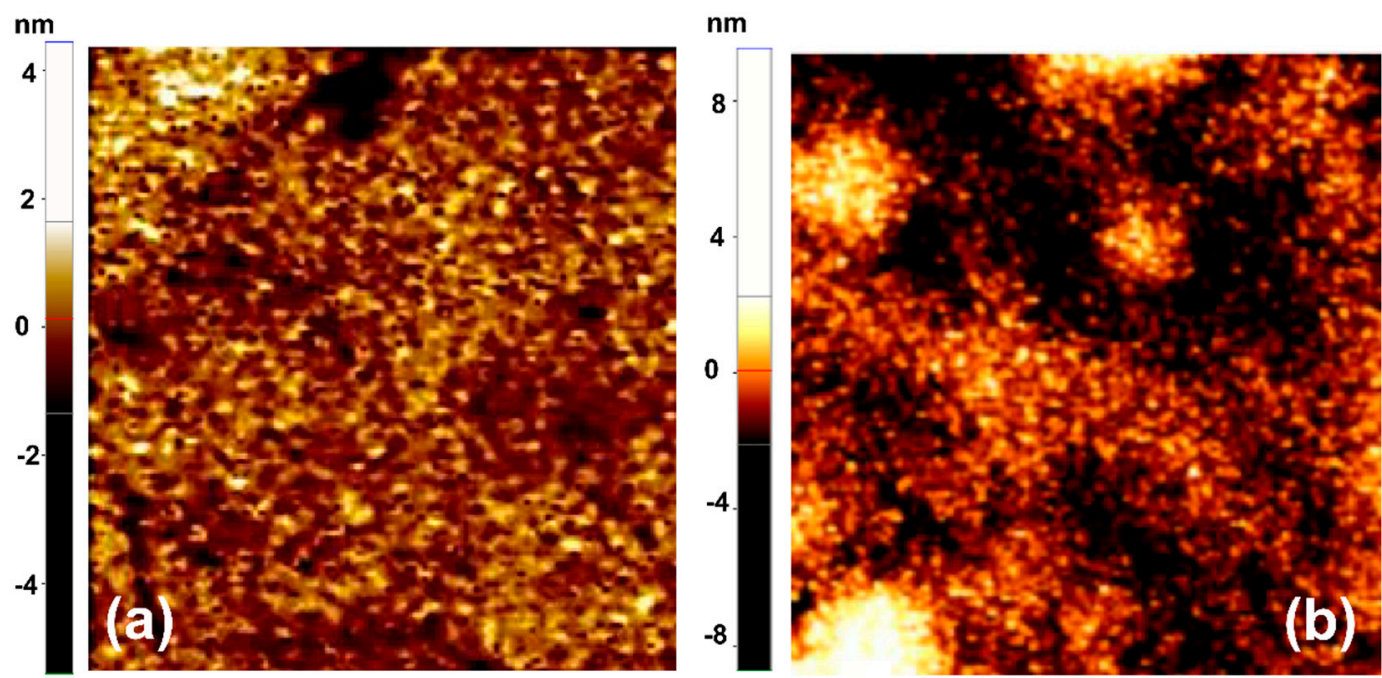

Figure 7. Atomic force microscope (AFM) images of (a) $5 \mathrm{~nm}$ and (b) $10 \mathrm{~nm}$ thick AlGaN surface scanned over $1 \mu \mathrm{m} \times 1 \mu \mathrm{m}$.

Figure 8a shows the $C-V$ data measured at room temperature. Here, $C-V$ characterization was performed at a frequency of $100 \mathrm{kHz}$ to reduce the measurement error arising from the series resistance. The carrier concentration vs. depth was obtained, as shown in Figure $8 \mathrm{~b}$. The carrier concentration of $\sim 8 \times 10^{16} \mathrm{~cm}^{-3}$ was obtained for $10 \mathrm{~nm}$ thick AlGaN, similar to the value provided by the vendor. However, $5 \mathrm{~nm}$ thick AlGaN was found to have a much higher value of $\sim 8 \times 10^{17} \mathrm{~cm}^{-3}$. For $n$-type semiconductors, the Schottky barrier height is:

$$
\Phi_{B}=q V_{b i}+k T / q \ln \left(N_{C} / N_{d}\right)=\Phi_{m}-\Phi_{s}+k T / q \ln \left(N_{C} / N_{d}\right)
$$

with $\Phi_{s}=q V_{0}+\chi+q\left|V_{S}\right|$, where $\Phi_{m}=5.65 \mathrm{eV}$ is the work function of $\mathrm{Pt}$ [26], $\Phi_{s}$ is the surface work function of $\mathrm{AlGaN}, \chi$ is the electron affinity of $\mathrm{AlGaN}$, and $q V_{S}$ is the surface band bending energy. By assuming that the electron affinity vs. $x$ in $\mathrm{Al}_{x} \mathrm{Ga}_{1-x} \mathrm{~N}\left(\chi_{\mathrm{GaN}}=4.2 \mathrm{eV}\right.$ and $\left.\chi_{\mathrm{AlN}}=2.05 \mathrm{eV}\right)$ varies linearly [18], we obtained $\chi=2.37 \mathrm{eV}$ for $\mathrm{Al}_{0.85} \mathrm{Ga}_{0.15} \mathrm{~N}$. Then, the barrier height can be written as:

$$
\Phi_{B}=\Phi_{m}-\chi-q\left|V_{S}\right|=3.28-q\left|V_{S}\right|
$$


By using the barrier heights from $C-V$ measurements, the surface state density $\left(N_{S}\right)$ was calculated through the following equation [27]:

$$
q\left|V_{S}\right|=\frac{\left(q N_{S}\right)^{2}}{2 \varepsilon \varepsilon_{0} N_{D}}
$$

where $\varepsilon$ is the dielectric constant of AlGaN. The surface state densities at AlGaN surface were found to be $3.9 \times 10^{12}$ and $1.1 \times 10^{12} \mathrm{~cm}^{-2}$, respectively, for 5 and $10 \mathrm{~nm}$ thick AlGaN. This clearly indicates the higher surface state density for $5 \mathrm{~nm}$ thick AlGaN. According to the thin surface barrier (TSB) model, the presence of surface donors can reduce the barrier width so that electrons tunnel through the thinner potential barrier easily [8,28]. Nitrogen vacancies and oxygen impurities in AlGaN may be the origin of surface donors $[29,30]$.
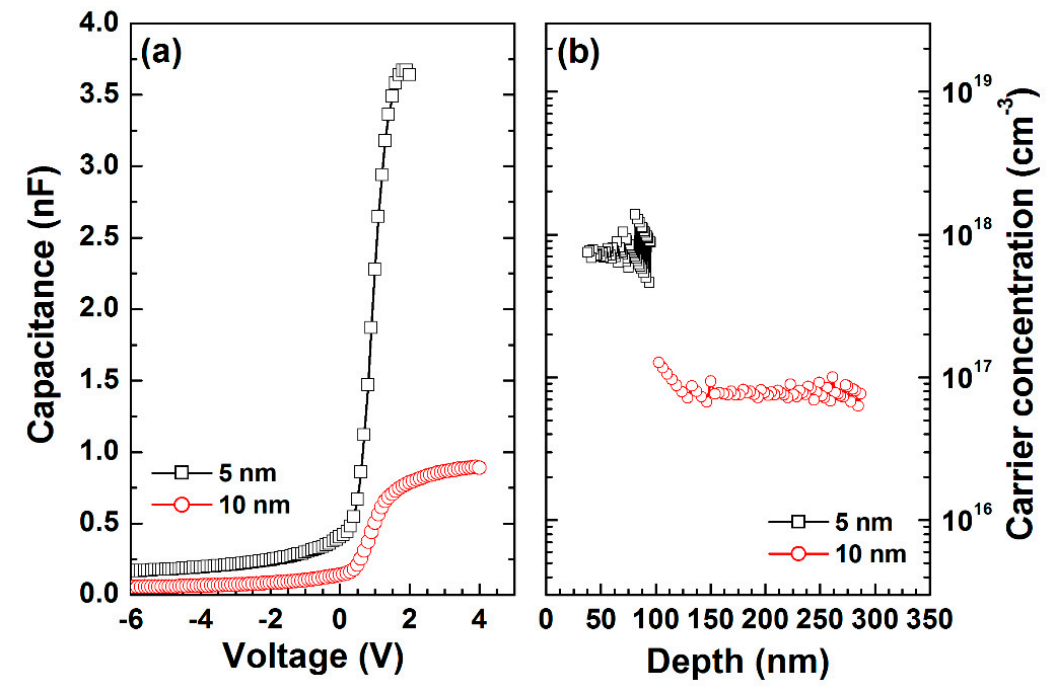

Figure 8. (a) Capacitance-voltage $(C-V)$ characteristics measured at $100 \mathrm{kHz}$ and (b) carrier concentration profiles vs. depth.

Because the interface states of a Schottky diode at the metal/semiconductor interface cannot follow the high-frequency signal, they do not contribute to the capacitance at high frequencies. Hence, the measured capacitance at a high-frequency consists of space-charge capacitance $\left(C \approx C_{S C}\right)$. At low-frequencies, the total capacitance consists of the space-charge capacitance $\left(C_{S C}\right)$ and the interface capacitance $\left(C_{i t}\right)$, which can be described as $C=C_{S C}+C_{i t}$ [31]. The interface state density $\left(N_{i t}\right)$ can be written as [32]:

$$
N_{i t}=\frac{C_{i t}}{q A}
$$

The interface state energy $\left(E_{i t}\right)$ below the conduction band $\left(E_{C}\right)$ at the semiconductor surface is given by $E_{C}-E_{i t}=\Phi_{B}-q V[31,32]$. The high and low-frequency $C-V$ characteristics were obtained at 500 and $1 \mathrm{kHz}$, respectively. Using Equation (12), the interface state density was calculated over the depletion region. Here, we conjecture that both the energy states at the AlGaN/GaN interface and near the $\mathrm{AlGaN}$ surface might contribute to the interface state density. As shown in Figure 9, the interface state density for $5 \mathrm{~nm}$ thick AlGaN was found to be higher. As a result, higher interface state density and a thinner AlGaN barrier layer might enhance the tunneling current for $5 \mathrm{~nm}$ thick AlGaN (i.e., direct tunneling could occur significantly) while the tunneling current is related to the TDs for $10 \mathrm{~nm}$ thick AlGaN (i.e., trap assisted tunneling might occur through TDs). Figure 10 shows the schematic band structures for each sample describing the dominant current transport mechanism. 


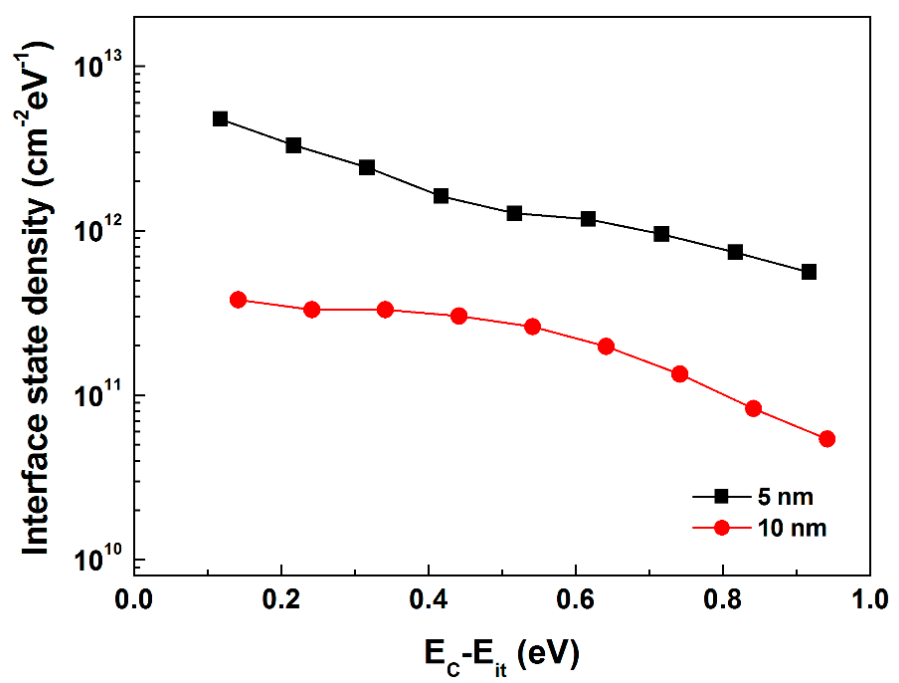

Figure 9. The energy distribution curves of the interface states obtained from the high- and low-frequency $C-V$ characteristics.

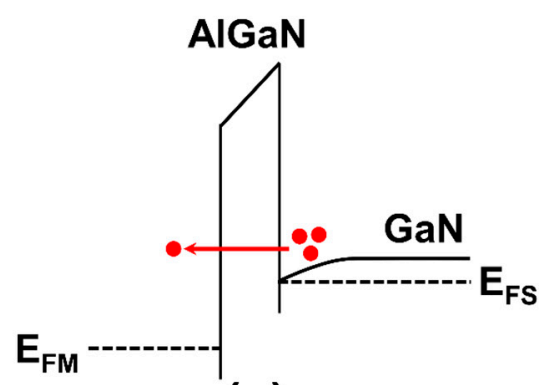

(a)

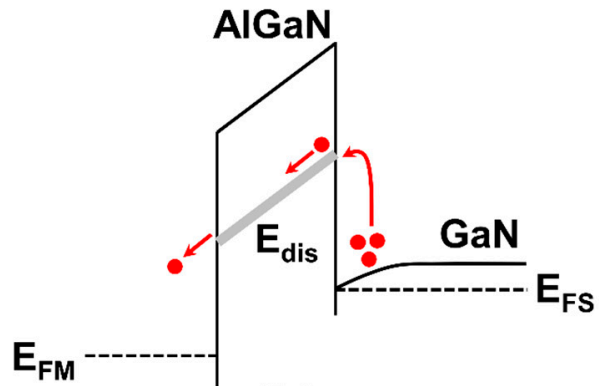

(b)

Figure 10. Schematic band diagrams presenting the dominant current transport under forward bias conditions for (a) 5 and (b) $10 \mathrm{~nm}$ thick AlGaN.

As shown in Figure 8a, both samples show that the transition from depletion to accumulation occurred above $0 \mathrm{~V}$, indicating that negative charges are present in the AlGaN layer. Normally $\mathrm{AlGaN} / \mathrm{GaN}$ Schottky diodes and HEMTs have the transition voltages as negative values $[11,33]$. Systematic investigation of thermal annealing on AlGaN/GaN HEMTs with different fluorine plasma treatment revealed the positive shift in the $C-V$ characteristics with the increasing of the plasma power, which negatively shifted after thermal annealing [34]. It was explained by the fact that $\mathrm{F}^{-}$ions introduced the acceptor-like states in the AlGaN barrier layer and subsequent annealing eliminated some plasma-induced trap states. When acceptor-like defects are present, $C-V$ curves stretch out in a positive direction [35]. Oxygen plasma treatment on AlGaN/GaN HEMTs was found to cause a positive shift, reducing the content of the $\mathrm{Al}$ component in the $\mathrm{AlGaN}$ barrier layer and depleting channel electrons [36]. The mechanism for positive flatband voltage shift and the depletion of electron gas due to oxygen plasma treatment was explained by gradual conversion of the AlGaN barrier layer into an $\mathrm{AlON} / \mathrm{GaON}$ structure [36]. The acceptor-like traps were associated with the oxidation of the recessed AlGaN surface during ALD growth [12]. Analysis on the X-ray photoelectron spectroscopy for $10 \mathrm{~nm}$ thick AlGaN (not shown) showed that the atomic percentage of oxygen atoms was about $15 \%$ in the AlGaN layer, indicating that the AlGaN layer is highly oxidized. Furthermore, 2DEG density according to the method by Lv et al. [37] was calculated to be about $1.1 \times 10^{12} \mathrm{~cm}^{2}$ for both samples. This is too low compared to other works [37,38]. During the ALD growth, many acceptor-like defects might be formed in the AlGaN layer and then, the electrons from the surface donors were captured while moving from the $\mathrm{AlGaN}$ surface to the $\mathrm{AlGaN} / \mathrm{GaN}$ interface, lowering the 2DEG density and forming the negative charges. Based on the study using post metallization annealing, it was proposed 
that the charges caused by interfacial defects could be passivated and neutralized through an $\mathrm{H}_{2}$-based annealing [39]. Thus, thermal annealing on ALD-AlGaN will be necessary to improve the interfacial quality of $\mathrm{AlGaN} / \mathrm{GaN}$ structure.

\section{Conclusions}

We characterized the current transport properties of AlGaN/GaN Schottky diodes with an ALD-grown AlGaN layer. At higher temperatures (above $348 \mathrm{~K}$ ), both 5 and $10 \mathrm{~nm}$ thick AlGaN showed that the TE model with Schottky barrier inhomogeneity was appropriate to explain the current flow. Higher barrier height for $10 \mathrm{~nm}$ thick AlGaN was obtained compared to $5 \mathrm{~nm}$ thick AlGaN. We fitted the experimental $I-V$ data to the theoretical values with the consideration of various transport mechanisms. The dislocation-governed tunneling model was matched well to the experimental data for $10 \mathrm{~nm}$ thick AlGaN, however, it was not applicable to $5 \mathrm{~nm}$ thick AlGaN. A higher density of surface (and interface) states was found for $5 \mathrm{~nm}$ thick $\mathrm{AlGaN}$, leading to a thinner tunneling barrier. Direct tunneling might occur significantly for $5 \mathrm{~nm}$ thick AlGaN while TD-related trap assisted tunneling was dominant for $10 \mathrm{~nm}$ thick AlGaN. Reducing the density of acceptor-like defects and minimizing the incorporation of oxygen atoms in AlGaN is highly required during the ALD growth. Even though the diode characteristics are not sufficiently good, the results obtained from this work will be meaningful for the understanding of the properties of ALD-AlGaN, in terms of both devices and materials. For example, the ALD growth can be applied to nanostructured layers with uniform thickness. In such nanoscale devices, the information obtained from the ALD-AlGaN layer is helpful in understanding device performance.

Author Contributions: Conceptualization, H.K.; methodology, H.K. and B.J.C.; investigation, H.K. and S.C.; writing-original draft, H.K.; writing-review and editing, H.K. and B.J.C. All authors have read and agreed to the published version of the manuscript.

Funding: This work was supported by the Basic Science Research Program through the National Research Foundation of Korea (NRF) funded by the Ministry of Education (2017R1D1A1B03030400).

Conflicts of Interest: The authors declare no conflict of interest.

\section{References}

1. Ibbetson, J.; Fini, P.; Ness, K.; DenBaars, S.; Speck, J.; Mishra, U. Polarization effects, surface states, and the source of electrons in AlGaN/GaN heterostructure field effect transistors. Appl. Phys. Lett. 2000, 77, $250-252$. [CrossRef]

2. Ambacher, O.; Smart, J.; Shealy, J.; Weimann, N.; Chu, K.; Murphy, M.; Schaff1, W.; Eastman, L.; Dimitrov, R.; Wittmer, L.; et al. Two-dimensional electron gases induced by spontaneous and piezoelectric polarization charges in N- and Ga-face AlGaN/GaN heterostructures. J. Appl. Phys. 1999, 85, 3222-3233. [CrossRef]

3. Ambacher, O.; Majewski, J.; Miskys, C.; Link, A.; Hermann, M.; Eickhoff, M.; Stutzmann, M.; Bernardini, F.; Fiorentini, V.; Tilak, V.; et al. Pyroelectric properties of Al(In)GaN/GaN hetero- and quantum well structures. J. Phys. Condens. Matter. 2002, 14, 3399-3434. [CrossRef]

4. Marcon, D.; Viaene, J.; Favia, P.; Bender, H.; Kang, X.; Lenci, S.; Decoutere, S. Reliability of AlGaN/GaN HEMTs: Permanent leakage current increase and output current drop. Microelectron. Reliab. 2012, 52, 2188-2193. [CrossRef]

5. Usami, S.; Ando, Y.; Tanaka, A.; Nagamatsu, K.; Deki, M.; Kushimoto, M.; Nitta, S.; Honda, Y.; Amano, H.; Sugawara, Y.; et al. Correlation between dislocations and leakage current of $\mathrm{p}$-n diodes on a free-standing GaN substrate. Appl. Phys. Lett. 2018, 112, 182106. [CrossRef]

6. Simpkins, B.; Yu, E.; Waltereit, P.; Speck, J. Correlated scanning Kelvin probe and conductive atomic force microscopy studies of dislocations in gallium nitride. J. Appl. Phys. 2003, 94, 1448-1453. [CrossRef]

7. Besendörfer, S.; Meissner, E.; Lesnik, A.; Friedrich, J.; Dadgar, A.; Erlbacher, T. Methodology for the investigation of threading dislocations as a source of vertical leakage in AlGaN/GaN-HEMT heterostructures for power devices. J. Appl. Phys. 2019, 125, 095704. [CrossRef] 
8. Hashizume, T.; Kotani, J.; Hasegawa, H. Leakage mechanism in GaN and AlGaN Schottky interfaces. Appl. Phys. Lett. 2004, 84, 4884-4886. [CrossRef]

9. Yan, D.; Lu, H.; Cao, D.; Chen, D.; Zhang, R.; Zheng, Y. On the reverse gate leakage current of AlGaN/GaN high electron mobility transistors. Appl. Phys. Lett. 2010, 97, 153503. [CrossRef]

10. Ha, W.; Chhajed, S.; Oh, S.; Hwang, S.; Kim, J.; Lee, J.; Kim, K. Analysis of the reverse leakage current in AlGaN/GaN Schottky barrier diodes treated with fluorine plasma. Appl. Phys. Lett. 2012, 100, 132104.

11. Ren, J.; Yan, D.; Zhai, Y.; Mou, W.; Gu, X. Comparison of electrical characteristics between AlGaN/GaN and lattice-matched InAlN/GaN heterostructure Schottky barrier diodes. Microelctron. Rel. 2016, 61, 82-86. [CrossRef]

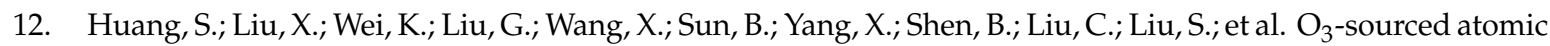
layer deposition of high quality $\mathrm{Al}_{2} \mathrm{O}_{3}$ gate dielectric for normally-off $\mathrm{GaN}$ metal-insulator-semiconductor high electron-mobility transistors. Appl. Phys. Lett. 2015, 106, 033507. [CrossRef]

13. George, S. Atomic layer deposition: An overview. Chem. Rev. 2010, 110, 111-131. [CrossRef]

14. Ozgit, C.; Donmez, I.; Alevli, M.; Biyikli, N. Atomic layer deposition of GaN at low temperatures. J. Vac. Sci. Technol. A 2013, 30, 01A124. [CrossRef]

15. Ozgit-Akgun, C.; Goldenberg, E.; Okyay, A.; Biyikli, N. Hollow cathode plasma-assisted atomic layer deposition of crystalline $\mathrm{AlN}, \mathrm{GaN}$ and $\mathrm{Al}_{x} \mathrm{Ga}_{1-x} \mathrm{~N}$ thin films at low temperatures. J. Mater. Chem. C 2014, 2, 2123-2236. [CrossRef]

16. Kim, H.; Kim, N.; An, S.; Yoon, H.; Choi, B. Improved interfacial properties of thermal atomic layer deposited AlN on GaN. Vacuum 2019, 159, 379-381. [CrossRef]

17. Tung, R. Recent advances in Schottky barrier concepts. Mater. Sci. Eng. R. 2001, 35, 1-138. [CrossRef]

18. Qiao, D.; Yu, L.; Lau, S.; Redwing, J.; Lin, J.; Jiang, H. Dependence of Ni/AlGaN Schottky barrier height on Al mole fraction. J. Appl. Phys. 2000, 87, 801-804. [CrossRef]

19. Suzue, K.; Mohammad, S.; Fan, Z.; Kim, W.; Aktas, O.; Botchkarev, A.; Morkoç, H. Electrical conduction in platinum-gallium nitride Schottky diodes. J. Appl. Phys. 1996, 80, 4467-4478. [CrossRef]

20. Donoval, D.; Chvála, A.; Šramatý, R.; Kováč, J.; Morvan, E.; Dua, C.; DiForte-Poisson, M.; Kordoš, P. Transport properties and barrier height evaluation in Ni/InAlN/GaN Schottky diodes. J. Appl. Phys. 2011, 109, 063711. [CrossRef]

21. Pelá, R.; Caetano, C.; Marques, M.; Ferreira, L.; Furthmüller, J.; Teles, L. Accurate band gaps of AlGaN, InGaN, and AlInN alloys calculations based on LDA-1/2 approach. Appl. Phys. Lett. 2011, 98, 151907. [CrossRef]

22. Wagner, A.; Young, W.; Sugerman, A. A note on the correlation between the Schottky-diode barrier height and the ideality factor as determined from I-V measurements. IEEE Electron Device Lett. 1983, 4, 320-322. [CrossRef]

23. Belyaev, A.; Boltovets, N.; Ivanov, V.; Klad'ko, V.; Konakova, R.; Kudrik, Y.; Kuchuk, A.; Milenin, V.; Sveshnikov, Y.; Sheremet, V. Mechanism of dislocation-governed charge transport in Schottky diodes based on gallium nitride. Semiconductors 2008, 42, 689-693. [CrossRef]

24. Tarsa, E.; Heying, B.; Wu, X.; Fini, P.; DenBarrs, S.; Speck, J. Homoepitaxial growth of GaN under Ga-stable and N-stable conditions by plasma-assisted molecular beam epitaxy. J. Appl. Phys. 1997, 82, 5472-5479. [CrossRef]

25. Moseley, M.; Allerman, A.; Crawford, M.; Wierer, J., Jr.; Smith, M.; Biedermann, L. Electrical current leakage and open-core threading dislocations in AlGaN-based deep ultraviolet light-emitting diodes. J. Appl. Phys. 2014, 116, 053104. [CrossRef]

26. Michaelson, H. The work function of the elements and its periodicity. J. Appl. Phys. 1977, 48, 4729-4733. [CrossRef]

27. Lee, C.; Lin, Y.; Liu, D. Schottky barrier height and surface state density of Ni/Au contacts to $\left(\mathrm{NH}_{4}\right)_{2} \mathrm{~S}_{x}$-treated n-type GaN. Appl. Phys. Lett. 2001, 79, 2573-2575. [CrossRef]

28. Hasegawa, H.; Susumu, O. Mechanism of anomalous current transport in n-type GaN Schottky contacts. J. Vac. Sci. Technol. B. 2002, 20, 1647-1655. [CrossRef]

29. Gordon, L.; Miao, M.; Chowdhury, S.; Higashiwaki, M.; Mishra, U.; Walle, C. Distributed surface donor states and the two-dimensional electron gas at AlGaN/GaN heterojunctions. J. Phys. D Appl. Phys. 2010, 43, 505501. [CrossRef] 
30. Hashizume, Y.; Kotani, J.; Basile, A.; Kaneko, M. Surface control process of AlGaN for suppression of gate leakage currents in AlGaN/GaN heterostructure field effect transistors. Jpn. J. Appl. Phys. 2006, 45, L111-L113. [CrossRef]

31. Özdemir, A.; Türüt, A.; Kökce, A. The interface state energy distribution from capacitance-frequency characteristics of gold/n-type Gallium arsenide Schottky barrier diodes exposed to air. Thin Solid Films 2003, 425, 2010-2015. [CrossRef]

32. Lee, C.; Lin, C.; Lee, H.; Chen, P. Changes in surface state density due to chlorine treatment in GaN Schottky ultraviolet photodetectors. J. Appl. Phys. 2008, 103, 094504. [CrossRef]

33. Enisherlova, K.; Goryachev, V.; Rusak, T.; Kapilin, S. Study of the effect of passivation layers on capacitance of AlGaN/GaN heterostructures. Modern Electron. Mater. 2016, 2, 131-137. [CrossRef]

34. He, Y.; Mi, M.; Zhang, M.; Wang, C.; Ma, X.; Hao, Y. Influence of Thermal Annealing on AlGaN/GaN HEMT by Fluorine Plasma Treatment. In Proceedings of the 2016 13th China International Forum on Solid State Lighting: International Forum on Wide Bandgap Semiconductors China (SSLChina: IFWS), Beijing, China, 15-17 November 2016; IEEE: Piscataway, NJ, USA, 2016; pp. 116-119.

35. Miczek, M.; Mizue, C.; Hashizume, T.; Adamowicz, B. Effects of interface states and temperature on the $C-V$ behavior of metal/insulator/AlGaN/GaN heterostructure capacitors. J. Appl. Phys. 2008, 103, 104510. [CrossRef]

36. He, Y.; Wang, C.; Mi, M.; Zheng, X.; Zhang, M.; Zhao, M.; Zhang, H.; Chen, L.; Zhang, J.; Ma, Z.; et al. Recessed-gate quasi-enhancement-mode $\mathrm{AlGaN} / \mathrm{GaN}$ high electron mobility transistors with oxygen plasma treatment. Chin. Phys. B. 2016, 25, 117305. [CrossRef]

37. Zhang, K.; Chen, X.; Mi, M.; Zhao, S.; Chen, Y.; Zhang, J.; Ma, X.; Hao, Y. Enhancement-mode AlGaN/GaN HEMTs with thin and high $\mathrm{Al}$ composition barrier layers using $\mathrm{O}_{2}$ plasma implantation. Phys. Status Solidi A. 2015, 212, 1081-1085. [CrossRef]

38. Lv, Y.; Lin, Z.; Corrigan, T.; Zhao, J.; Cao, Z.; Meng, L.; Luan, C.; Wang, Z.; Chen, H. Extraction of AlGaN/GaN heterostructure Schottky diode barrier heights from forward current-voltage characteristics. J. Appl. Phys. 2011, 109, 074512. [CrossRef]

39. Hung, T.; Krishnamoorthy, S.; Esposto, M.; Nath, D.; Park, P.; Rajan, S. Interface charge engineering at atomic layer deposited dielectric/III-nitride interfaces. Appl. Phys. Lett. 2013, 102, 072105. [CrossRef] 